\title{
- Hybrid Power and Propulsion
}

\author{
Paolo Scialla ${ }^{1} \quad$ Peter Davies $^{2} \quad$ Edward Fort $^{3}$
}

\author{
1Lloyd's Register Marine \& Offshore, Trieste, Italy \\ 2,3Lloyd's Register Marine \& Offshore, Southampton, UK
}

\section{Introduction}

The 'decarbonisation' of shipping is without doubt the greatest challenge that the industry now faces and indeed, arguably, the greatest challenge that transportation in general faces. Accordingly, while safety remains paramount, decarbonisation is now firmly at the heart of Lloyd's Register's strategy. If shipping is to achieve the demanding carbon reduction targets set down by the International Maritime Organisation $^{(1)}$, every aspect of the industry will need to be examined, from ship finance, ship chartering, fleet management and ship operations to, of course, ship design and construction. Change will need to be both evolutionary and revolutionary such is the challenge.

From a global perspective, there is little doubt that international shipping is a highly effective operation facilitating over $90 \%$ of world trade. The workhorse of this operation - the large diesel engines which power the oceangoing fleet - convert residual fuel oils (the residues of the petroleum refining industry, the leftovers of our modern industrial society thus) into power for propulsion and in doing so, achieve unparalleled efficiency. Despite such performance however, the high carbon content of residual fuel oil multiplied by the many tons of fuel oil consumed daily by each ship means that collectively the industry is responsible for sizable proportion of the world's carbon emissions.

In tackling the challenge of decarbonisation, Lloyd's Register is examining all aspects of shipping falling within its sphere of influence and technical competence from both near and longer-term perspectives. Revolutionary concepts under evaluation include the safety and viability of zero carbon ship fuels, generated using renewable energy, such as ammonia and hydrogen. Other revolutionary concepts include all-electric ships based entirely on fuel cell power generation, advanced battery and renewable energy technologies. Perhaps more evolutionary than revolutionary and very much more near term are electro-mechanical 'hybrid' vessels. Such vessels typically combine conventional diesel engines with advanced batteries and electrical motors and offer immediate reductions in fuel oil consumption, reductions in harmful emissions and increases in dependability using currently available technologies.

\section{Hybrid Innovation}

The hybrid concept was first commercialized in the automotive industry with the introduction of the Toyota Prius in 1997. The Prius is based on electro-mechanical technology being powered by a conventional petrol engine drive train supplemented by electric motor drive powered by a rechargeable battery. Propulsion is optimised by managing both electric motors and engine to provide power to wheels. Following the Toyota innovation most other major car manufacturers have released hybrid road vehicles. Commercial vehicles have also begun to make use of the technology including buses, construction machinery, boats and aircraft.

The term hybrid is used with reference to a wide variety of energy storage, power generation and power distribution configurations. Within the transportation industry a hybrid power system is generally recognized as one in which two or more 
different sources of power together satisfy all onboard power demands. Such arrangements are not new to the marine industry. Driven primarily by peak power, power density and dynamic performance demands the use of diesel engines in combination with gas turbines (CODAG) is common in naval ships while the use of gas turbines in combination with steam turbines to generate electrical power (COGES) has been utilised within the passenger ship segment. However, more recently, responding to different set of drivers, hybrid power systems combining diesel engines and advanced batteries are becoming increasing common due to unique operating features and are set to dominate particular ship segments for the immediate future.

\section{Hybrid Drivers}

The reduction in harmful emissions has become a primary driver in the design of ships. Tightening maritime regulations, both international and local, are challenging ship design fundamentals. Driven by public opinion, discharges to water and emissions to air are increasingly the focus of the industry's regulators. Airborne emissions of sulphur oxides (SOx), nitrous oxides (NOx) and carbon dioxide (CO2) are now directly or indirectly limited by regulations or incentives. Other potentially harmful emissions such as Particulate Matter (PM), airborne and waterborne noise are also under scrutiny. Nowhere is this more apparent that for vessels operating close to centers of population particularly inshore in estuaries, rivers, ports and harbours.

While zero emission power generation solutions for the bulk of the world's ocean going shipping fleet are some way off, for vessels with limited energy demands, limited onboard energy storage requirements and the ability to bunker frequently such as tugs, ferries, patrol boats etc., hybrid power generation and propulsion offers an immediate zero emission solution under certain circumstances.

\section{Hybrid Systems}

The underlying concepts of hybrid road vehicles apply equally to hybrid ships. Both use a combination of different sources of power to supply all onboard power demands. However, one significant difference, between hybrid road vehicles and hybrid ships is the recovery of braking energy. The lack of direct adhesion between the propeller and the water makes it difficult to recover energy during braking aboard ships. This results in smaller savings through the use of hybrid drive concepts compared to road vehicles.

Most of the worlds ocean going ships employ either mechanical propulsion arrangements, in which diesel engines drive propellers directly or indirectly through a gearbox, or alternatively employ diesel-electric power and propulsion arrangements in which diesel engines drive electrical generators which supply propulsion motors and in parallel provide electrical power to the ships electrical system.

A typical hybrid power and propulsion system essentially combines the two arrangements together such that the propeller may be driven by a diesel engine and/or an electric motor powered by the ship's electric system (See Fig.1).

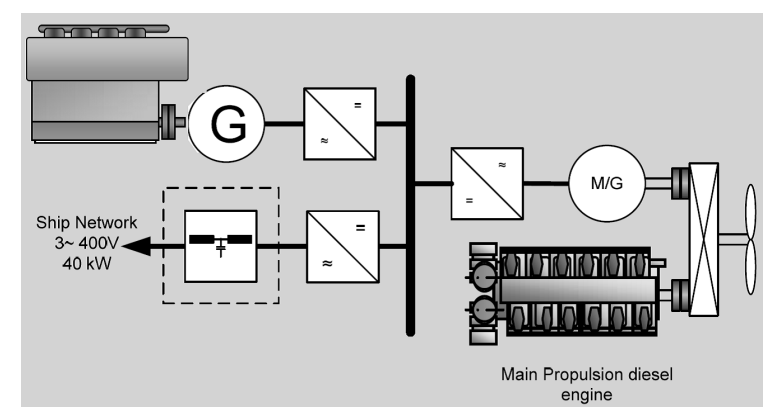

Figure 1. Example of hybrid power and propulsion (courtesy of Siemens)

Electrical power distribution may be either Alternating Current (AC) or Direct current (DC) or a combination of both. The introduction of a DC distribution link provides a number of benefits not least the ability to readily integrate batteries thereby increasing the flexibility of the system by providing a source of stored energy that can contribute to propulsion and potentially can provide all power needed for low speed and short time navigation (See Fig. 2). 


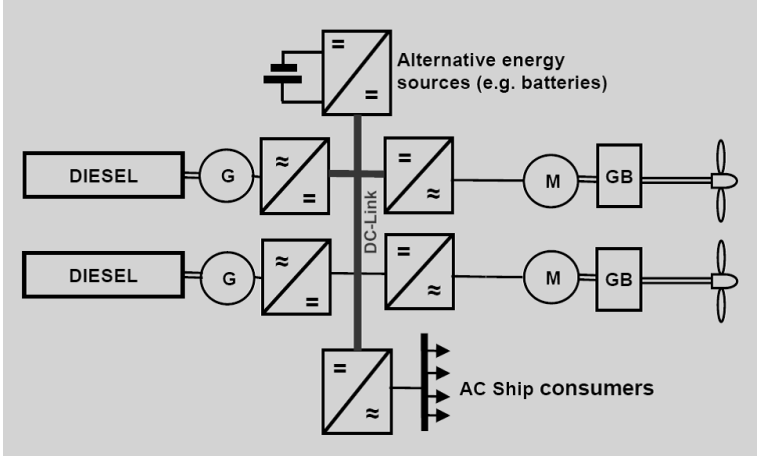

Figure 2. Example of hybrid power and propulsion system with energy storage (courtesy of Siemens)

\section{Hybrid Power}

In addition to the conventional propulsion and power generation system technologies hybrid power and propulsion systems draw upon several technologies not traditionally associated with ship power generation and propulsion including advanced batteries, fuel cells, photovoltaic arrays and super capacitors. Of these, almost all recently constructed hybrid vessels have included advanced batteries. While batteries are commonplace onboard ships, their use in supplying power for propulsion is a relatively recent development.

A number of advanced battery technologies are available but the most widely used for hybrid power and propulsion systems is Lithium-ion (Li-Ion). Well established technologies such as Lead Acid, Nickel Cadmium (NiCd) and Nickel Metal Hydride (NiMH) cannot compete with the performance offered by Li-Ion technology, even taking account of the increased costs per Wh. Li-Ion cells have a high voltage, up to $3.7 \mathrm{~V}$, about three times the nominal voltage of $\mathrm{NiCd}$ and $\mathrm{NiMH}$ cells which means a reduced number of cell interconnections and electronics are required to achieve usable voltage levels. The comparison is similar for energy density, very often the deciding factor for transport applications. The energy density of Li-ion cells is over twice that of NiMH cells and over three times that of $\mathrm{NiCd}$ cells. However, compared to Lead Acid, NiCd and $\mathrm{NiMH}$ technologies, Li-Ion technology introduces some significant additional hazards. Most Li-Ion metal oxide electrodes are thermally unstable and can decompose at elevated temperatures resulting in a rapid, high energy, exothermic reaction (known as thermal runaway). To mitigate the risk of such undesirable behavior Li-Ion batteries require monitoring systems to prevent over charging and discharging and other abnormal conditions that can lead to thermal runaway.

Other high-performance battery technologies include Sodium Sulphur (NaS) and Sodium Nickel Chloride (NaNiCl) technologies both of which become operational at high temperatures, typically over 250 Deg.C. $\mathrm{NaNiCl}$ technology, commercially known as the ZEBRA (Zero Emissions Batteries Research Activity) battery, has been successfully utlised in several electric vehicle designs (Think City, Smart EV) and, within the marine industry, in the NATO Submarine Rescue System (NSRS). As battery technology continues to evolve it is almost certain that future battery technologies offering significantly improved performance will at some point displace Li-Ion technology in hybrid power and propulsion applications. One such potential successor, Metal Air (Me-Air) technology, is currently under consideration in view of its theoretical energy density being in the order of a magnitude greater than the best performing Lithium cells currently available.

Another technology expected to become a common feature in future hybrid ships is the fuel cell generator. Fuel cell generators offer the potential for highly efficient, highly reliable, solid state, emission free power generation. Like a battery, electrical power is generated through an exothermic chemical reaction (the reverse of electrolysis of water) rather than combustion, thus eliminating the harmful emissions associated with combustion. Unlike a battery however, the reaction can continue indefinitely so long as fuel and air is supplied in a similar manner to a conventional electrical generator. In the longer term, fuel cell generators have the potential to displace diesel engines however in the near term they are likely to be combined with diesel engines in hybrid power and propulsion systems. Fuel cell technology has been widely utilized in transportation applications including spacecraft, submarines, trains, buses, passenger vehicles and ships. 


\section{Hybrid Applications}

Harbour tugs, inshore ferries and patrol boats typically have operating profiles that are ideally suited for hybrid power and propulsion systems. A harbour tug having 60 tonnes of bollard pull will typically comprise twin propulsion lines of about $2000 \mathrm{~kW}$ each. The operational profile for such a tug over the year reveals that approximately $30 \%$ of time is spent alongside awaiting a tow (See Fig. 3)

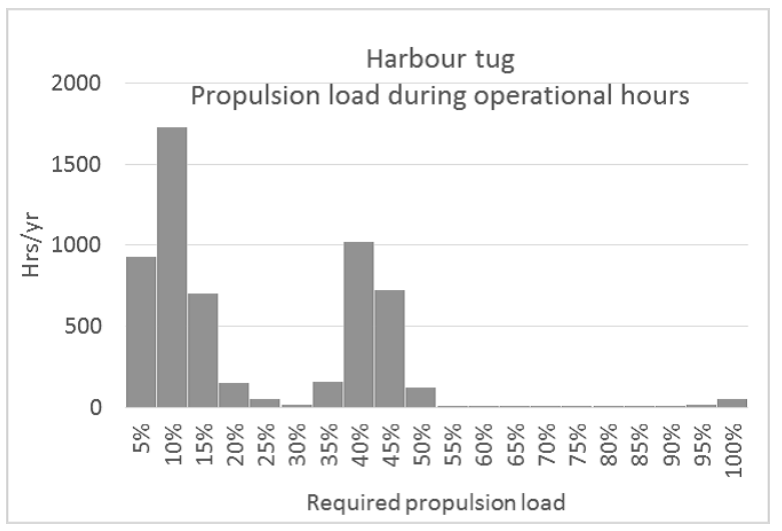

Figure 3. Example of annual load profile for harbor tug (courtesy of HyPS)

When in operation, the tug spends a long time either at low load (station keeping, running idle) or with medium load during transit (free sailing) and towing along with very short periods of bollard pull. Since the power generation and propulsion system of a conventional harbour tug is designed according to the required maximum bollard pull, the long periods of time the tug spends operating at low load (the majority of the operational time) results in very poor Specific Fuel Oil Consumption (SFOC) and as a consequence unnecessarily high levels of harmful emissions.

For the operational profile described, a hybrid power and propulsion system is extremely well suited. Two main engines with two electric rotating machines capable of operating in Power Take Off (PTO) modes and Power Take In (PTI) modes is considered as an appropriate solution. The arrangement can be further optimized by the addition of a DC link and a battery bank. The hybrid system is thus essentially a combination of direct mechanical and diesel-electric propulsion systems with the addition of an energy storage system.
With such a system, the ability to utilize combinations of different power sources according to power demand allows the shutdown of the diesel engines at low load. Besides improving SFOC and reducing or totally eliminating emissions this also results in reduced machinery noise and reduced engine maintenance. The selection and optimization of available power sources according to the operational profile is carried out automatically by an energy and power management system. The operator on the bridge selects the most appropriate operating mode of which the following are typical:

Zero emission or stand-by mode. Diesel propulsion engines and diesel gensets are shutdown. The battery pack supplies all electrical loads and the electric propulsion motor (acting as PTI). This mode is also called discharging or 'green mode' since the battery pack is the sole source of power and the tug operates with zero-emissions. Where the battery pack has enough power, the stand-by mode can be used for station keeping, maneuvering and free sailing at low speeds.

Sailing mode. Diesel propulsion engines are shutdown. Diesel gensets supply the electric propulsion motor (in PTI mode) and all electric loads. The battery pack can either contribute to supplying electrical loads (peak shaving - PTO mode) or be re-charged according to the energy management system settings for the charging/discharging operations. Sailing mode can be used for station keeping, maneuvering and free sailing at speeds higher than those achievable in the stand-by mode.

Towing or power boost mode. Diesel propulsion engines are running and supplying power for propulsion. Diesel gensets are running and supplying electrical loads. The battery pack can either boost propulsion power (in PTI mode), contribute to supplying electrical loads (peak shaving PTO mode) or be re-charged according to the energy management system settings for the charging/discharging operations. The towing mode is used during push/pull operations and free sailing at the maximum speed.

There may also be additional secondary modes of operation based on the availability 
of battery energy such as the starting of the engines and battery re-charging in port by using appropriate shore connection facilities. Such a variety of potential operating modes necessitates an energy and power system that monitors and controls the system machinery, equipment and components including propulsion engines, gensets, main switchboard, propulsion converters, motors and batteries.

\section{Hybrid Rules and Regulations}

Many of the ongoing developments within hybrid power and propulsion systems relate to the increased utilization of DC current for a number of beneficial reasons. Medium Voltage DC (MVDC) networks offer efficiency gains through reduction of impedance and eliminating reactive current losses while the absence of frequency considerations permits diesel engines to be run at their optimum speed for maximum efficiency or minimum emissions. Although AC networks need much simpler circuit breaking technology than DC networks, since electrical arcs clear themselves at zero-crossing of the current waveform, DC fault currents can be successfully managed and faults cleared by utilizing the speed of response of power electronics. Overall a general reduction in weight and space of DC equipment can be expected.

Such differences highlight some of the fundamental differences between conventional power generation and propulsion systems and hybrid systems. The well-established Classification Society Rules and Regulations ${ }^{(2)}$ are, for the most part, focused exclusively on conventional AC power generation systems and conventional diesel driven propulsion systems and additional consideration needs to be given to the operational and safety issues associated with the DC equipment and components and the advanced energy storage and power conversion technologies associated with hybrid systems.

Potential fire and explosion hazards associated with advanced energy storage technologies such as lithium batteries typically result from mechanical failure, thermal runaway, internal overpressure or poor energy management. Risk mitigations include battery manufacturing quality assurance and the appropriate design of fire-fighting systems specifically suited to the battery chemistry characteristics. Because of the additional hazards introduced by hybrid power and propulsion systems which are not necessarily address by the extant prescriptive Rules and Regulations, to date Lloyd's Register has used a risk based approach to the approval of hybrid systems employing DC equipment and advanced energy storage technologies ${ }^{(3)}$.

As well as the expected operating scenarios, such risk assessments have also taken into consideration reasonably foreseeable abnormal conditions including those resulting from equipment failure and human error. Using the knowledge acquired from the many such risk assessments, which have been undertaken with many different subject matter experts from across the world, Lloyd's Register has commenced the development of a dedicated set of requirements for hybrid power and propulsion systems which, together with the knowledge acquired, will incorporate the essential elements of Lloyd's Register's existing Provisional Rules for DC distribution systems ${ }^{(4)}$ and guidelines for advanced batteries ${ }^{(5)}$. The requirements will aim to achieving a level of safety and dependability for hybrid power and propulsion systems equivalent to that achieved for conventional power generation and propulsion systems while removing any constraints that hinder the full optimization of such hybrid systems.

\section{Conclusions}

The decarbonisation of shipping is without doubt the greatest challenge now facing the industry. If shipping is to achieve the demanding carbon reduction targets set down by the International Maritime Organisation ship design will need to undergo both revolutionary and evolutionary change. Revolutionary change, in the shape of widely available, commercially viable, zero carbon fuels is some way off, as are all-electric ships.

Evolution however is happening now. Rapidly becoming the norm in certain ship segments hybrid power and propulsion systems are lowering fuel consumption and costs while reducing or completely 
eliminating emissions of $\mathrm{SOx}, \mathrm{NOx}$ and $\mathrm{CO} 2$ when operating close to centers of population. Such hybrid vessels provide a platform for the introduction of clean fuels and high-density energy storage technologies

\section{References}

(1) IMO MEPC Resolution 304(72)

(2) Rules and Regulations for the Classification of Ships, Lloyd's Register, July 2017

(3) ShipRight Design and Construction Additional Design Procedures Risk Based Design (RBD), Lloyd's Register, May 2016

(4) Provisional Rules for Direct Current

Distribution Systems, Lloyd's Register, Jan 2015

(5) Battery Installations - Key hazards to consider and Lloyd's Register's approach to approval, Lloyd's Register, Jan 2016

\section{Authors}

- Scialla, Paolo (1)

- Electrotechnical Lead

-Lloyd's Register Marine \& Offshore, Trieste, Italy

- Davies, Peter (2)

- Principal Surveyor

- Lloyd's Register Marine \& Offshore,

Global Technology Center, Southampton, UK

- Fort, Edward (3)

- Global Head of Engineering

- Lloyd's Register Marine \& Offshore,

Global Technology Center, Southampton, UK that will allow the industry to overcome the decarbonization challenge. 